\title{
Cholecystocolonic fistula presenting as a lower gastrointestinal bleeding: Preoperative work-up, treatment options, and literature review
}

\author{
Marc J. Dauer, Oscar K. Serrano \\ Department of Surgery, Montefiore Medical Center, Albert Einstein College of Medicine, New York, USA
}

Received: July 10, 2016

DOI: $10.5430 /$ ijdi.v4n1p20
Accepted: September 25, $2016 \quad$ Online Published: October 31, 2016

URL: http://dx.doi.org/10.5430/ijdi.v4n1p20

\begin{abstract}
Cholecystocolonic fistulae are the second most common choloenteric fistulae, yet only a small percentage are diagnosed preoperatively. This lack of preoperative recognition often leads to intraoperative discovery, leaving little opportunity for preoperative planning. Herein, we present the case of a 59-year-old male who presented with a cholecystocolonic fistula, manifested by lower gastrointestinal bleeding. Recognition of the fistula allowed for medical optimization and preoperative planning. There is currently a shortage of data on the ideal management of cholecystocolonic fistulae. We review the literature on cholecystocolonic fistulae and discuss the alternatives and controversies to the optimal management.
\end{abstract}

Key Words: Gastrointestinal hemorrhage, Fistulae, Cholecystocolonic fistulae, Surgery

\section{INTRODUCTION}

Cholecystoenteric fistulae (CEF) are an uncommon yet serious complication of longstanding cholelithiasis and cholecystitis. There are many different types of CEF with choleduodenal fistulae being the most common, comprising $62 \%$ of reported cases, followed by cholecystocolonic fistulae (CCCF), and cholecystogastric fistulae. ${ }^{[1]}$ Although CEF is only present in $0.4 \%-1.9 \%$ cases of gallbladder disease, they are associated with a mortality rate of $15 \%-30 \%$ worldwide $^{[1-3]}$ This phenomenon is most pronounced among patients with the often-undiagnosed CCCF. Typically, CCCF form as a communication between the gallbladder and a segment of colon, near the hepatic flexure. Most patients with CCCF do not present with the classic symptoms of cholelithiasis, but rather vague non-specific symptoms including diarrhea, lower gastrointestinal bleeding (LGIB), and large bowel obstruction, making the diagnosis very difficult. ${ }^{[4]} \mathrm{A}$ delay in diagnosis of CCCF places patients at increased risk for complications such as biliary cirrhosis, acute cholangitis, chronic diarrhea, and biliary peritonitis. ${ }^{[5]}$

Surgical management of CCCF is challenging and has been a subject of debate. Preoperative assessment is paramount for surgical planning as it provides the opportunity of adequate preparation for intraoperative and postoperative care, thereby minimizing complication rates. Only $7.9 \%$ of CCCF are diagnosed preoperatively, with the majority discovered incidentally during exploration. ${ }^{[6]}$ We present a case of a patient with CCCF who presented with hematochezia and hemorrhagic shock who, upon further evaluation, was found to have a CCCF on CT-angiogram (CTA) and colonoscopy preoperatively.

\footnotetext{
*Correspondence: Marc J. Dauer, MD; Email: Mdauer@montefiore.org; Address: Montefiore Medical Center, Albert Einstein College of Medicine, Greene Medical Arts Pavilion, 4th Floor, 3400 Bainbridge Ave, New York, NY 10467, USA.
} 


\section{CASE REPORT}

We present a 59-year-old Hepatitis C-positive, former IV drug user, with a prior history of a splenectomy for blunt trauma, who presented to the Emergency Department (ED) after suffering a syncopal episode at home and several episodes of bright red blood per rectum and diarrhea. He had a history of a LGIB one year prior to presentation that resolved without any medical treatment. In the ED, the patient was hypotensive and had a hemoglobin level of $7 \mathrm{mg} / \mathrm{dl}$. He was transfused three units of packed red blood cells (PRBC) and his hemoglobin increased to $11 \mathrm{mg} / \mathrm{dl}$. He denied having a colonoscopy or endoscopy in the past. His physical exam findings included a protuberant non-tender abdomen with hypoactive bowel sounds and gross blood in his rectal vault. A CTA was performed, which demonstrated a descending and rectosigmoid colon filled with high density fluid, likely to be blood, but no evidence of active gastrointestinal bleeding. Moreover, his CTA demonstrated cholelithiasis with mild stranding around the gallbladder and a fistulous tract between the gallbladder and hepatic flexure of the colon (see Figure 1A, D). After initial stabilization and adequate bowel preparation, a colonoscopy was performed which showed a $2 \mathrm{~cm}$ clot adherent to the colonic mucosa with leakage of purulent sanguineous material at the suspected site of the CCCF (see Figure 1B). The patient had no further episodes of bleeding and remained hemodynamically stable.

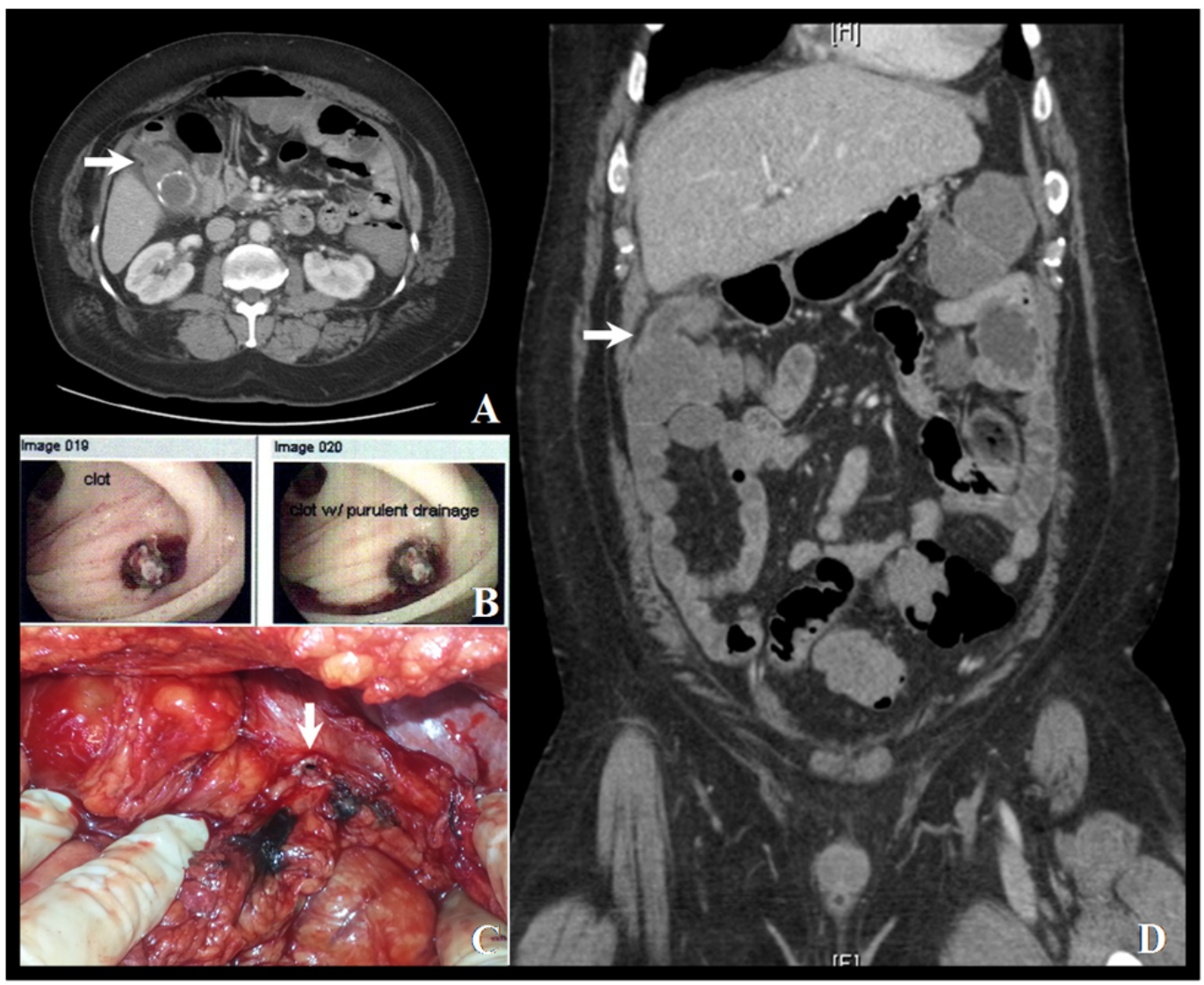

Figure 1. CT angiogram demonstrating an impacted stone in the infundibulum of the gallbladder. There is large caliber fistulous tract between the gallbladder and hepatic flexure of the colon (arrow) which can be readily identified on cross-section (A) and coronal (B) images. The fistula tract was found to be the source of hemorrhage on colonoscopy (C). Operative exploration identified the location of the fistulous tract to be the antimesenteric boarder of the hepatic flexure (D)

The patient was taken to the operating room for exploration. A 5-mm fistulous tract was identified from the gallbladder infundibulum to the transverse colon (see Figure 1C). A $10 \mathrm{~cm}$ segment of transverse colon was resected and a cholecystectomy was performed. The pathology demonstrated areas of disrupted mucosa within the colon with both chronic and acute inflammation representing the fistula tract. The resection margins of the colon showed mild acute serositis with fibrous adhesions.

Postoperative recovery was complicated by prolonged requirement for mechanical ventilation. However, the patient regained bowel function on postoperative day 5 , shortly after 
enteral feeds were initiated. Eventually, he was discharged to a rehabilitation facility. On follow up appointments, the patient's recovery was uneventful and returned to his baseline functional status within a month of surgery.

\section{Discussion}

Despite their rare incidence, $\mathrm{CCCF}$ pose a unique problem due to their indolent nature and difficulty of diagnosis. Less than $8 \%$ of CCCF are diagnosed preoperatively, compared to more than $43 \%$ of other types of cholecystoenteric fistulae. ${ }^{[7,8]}$ Their elusive clinical presentation and lack of characteristic signs and symptoms makes CCCF a difficult diagnosis to ascertain. The most common symptoms on presentation are right sided abdominal pain, fever, and jaundice signs typical for cholangitis. Other less common presentation are colonic obstruction from biliary stones, lower GI bleeding $(23 \%)$ and hepatic abscess $(6 \%)$. In patients with chronic $\mathrm{CCCF}$, the most typical presenting symptom include chronic diarrhea, which is found in over $71 \%$ of patients. ${ }^{[4]}$ Common modalities used to diagnose biliary tract disease such as ultrasound and cholescintigraphy often miss CCCF. ${ }^{\text {9] }}$ Our patient presented with a LGIB, which prompted a CTA. CT scans, albeit not normally ordered in patients with signs and symptoms of cholelithiasis, have been shown to be quite useful in diagnosing CCCF. ${ }^{[8,10]}$ Due to this combination of non-specific signs and symptoms and poor sensitivity of imaging modalities, CCCF is very difficult to diagnose and most cases are found incidentally.

The literature is scant on the optimal surgical treatment of CCCF. Since most CCCF are discovered incidentally during routine laparoscopic cholecystectomy, ${ }^{[6]}$ the dilemma arises on whether laparoscopic repair should be entertained as opposed to exploring the patient through a laparotomy. There is compelling evidence against a laparoscopic approach unless the operating surgeon is especially adept with this type of surgery. These cases are typically associated with longer intraoperative time, increased laparoscopic complications, and a conversion rate greater than $55 \%$ of the time. ${ }^{[3,11]}$ The choice for open laparotomy should be tailored according to the surgeon's comfort, the patient's co-morbidities and surgical history to minimize intraoperative time and injury. ${ }^{[4]}$ Older patients with multiple comorbidities have a higher complication rates and should be treated more conservatively. ${ }^{[12,13]}$ In our patient, an open laparotomy and resection was chosen due to the patient's medical co-morbidities, presenting symptoms, prior surgical history for trauma, and the need to rule out malignancy, seen in $6 \%-14 \%$ of $\mathrm{CEF}$ cases. ${ }^{[14]}$ Furthermore, CCCF are typically a manifestation of chronic hepatobiliary disease with challenging anatomy, arguing against a laparoscopic approach.
A second consideration that should be entertained is the option of primary closure of the CCCF or a formal colonic resection, which requires an anastomosis. The latter could also be performed in conjunction with a diverting ileostomy, if the resection puts the anastomosis at risk of leak. The decision for primary closure versus a colonic resection should be based on a variety of preoperative and intraoperative factors, including the presence gallstone ileus, obstruction or bleeding. ${ }^{[4,15]}$ Our patient had a LGIB and the margin around the CCCF was felt to be friable and not ideal for primary repair. Therefore, we felt that a segmental resection with a primary anastomosis was appropriate since this has been previously shown to decrease the occurrence of future GI bleeding. ${ }^{[16]}$ Perhaps, in patients with a small defect or no signs of bleeding, a primary repair may suffice; however, CCCF defects have been demonstrated to harbor areas of chronic inflammation, not optimal for wound healing. [17] In that case, a segmental resection with re-anastomosis of healthy bowel margins should be undertaken, if possible. ${ }^{[18]}$ In patients that are hemodynamically unstable, have multiple co-morbidities, or are septic, it would be acceptable to do a diverting ileostomy at the time of surgery. ${ }^{[19]}$ In our case, the patient had no recurrence of LGIB and was hemodynamically stable throughout the case.

Lastly, after a comprehensive literature review on CCCF and LGIB four additional case reports were discovered. In three of the four cases a diagnosis was made with a CT scan. The causes of LGIB in two of the cases were identified as a right hepatic artery pseudo-aneurysm and cystic artery pseudoaneurysm. Unfortunately, only one of the papers discussed their treatment method, which was similar to ours, including an exploratory laparotomy, partial colectomy and fistula takedown. Overall, the herald sign was a lower GI bleed, which prompted a CT scan, that ultimately led to the diagnosis. This, in turn, allowed for pre-operative planning, which is rare in $\mathrm{CCCF}^{[16,20-23]}$

\section{Conclusion}

Herein, we present a case of a CCCF that presented with LGIB. The utility and importance of CT scan and colonoscopy in identifying the CCCF was demonstrated and how these imagining modalities factored into the preoperative decision-making. A high index of suspicion for CCCF is necessary when evaluating patients with a history of chronic cholelithiasis with diarrhea and LGIB. In our case, the adequate preoperative identification of CCCF was ascertained, which enabled us to design a patient-specific surgical plan, utilizing an open technique and a formal colon resection, resulting in an optimal outcome for the patient. In the setting of an incidentally discovered CCCF during laparoscopic 
surgery, a low threshold for conversion to an open procedure should be employed to allow the adequate exploration, based on the surgeon's comfort level and the patient's frailty and prior surgical history. Given the rare incidence of $\mathrm{CCCF}$, further data is necessary on long-term outcomes.

\section{CONFLICTS OF INTEREST Disclosure}

The authors have declared no conflicts of interest.

\section{REFERENCES}

[1] Yamashita H, Chijiiwa K, Ogawa Y, et al. The internal biliary fistulareappraisal of incidence, type, diagnosis and management of 33 consecutive cases. HPB Surg. 1997; 10: 143-147. PMid:9174858 http://dx.doi.org/10.1155/1997/95363

[2] Atli AO, Coşkun T, Ozenç A, et al. Biliary enteric fistulas. Int Surg. 1997; 82: 280-283. PMid:9372375

[3] Inal M, Oguz M, Aksungur E, et al. Biliary-enteric fistulas: report of five cases and review of the literature. Eur Radiol. 1999; 9: 11451151. PMid: 10415254 http://dx.doi.org/10.1007/s003300 050810

[4] Costi R, Randone B, Violi V, et al. Cholecystocolonic fistula: facts and myths. A review of the 231 published cases. J Hepatobiliary Pancreat Surg. 2009; 16: 8-18. PMid:19089311 http://dx.doi.o $\mathrm{rg} / 10.1007 / \mathrm{s} 00534-008-0014-1$

[5] Gullino D, Giordano O, Cardino L, et al. Complication of spontaneous internal biliary fistulae (experiences in 46 cases). Minerva Chir. 1977; 32: 1221-1238. PMid:339127

[6] Chowbey PK, Bandyopadhyay SK, Sharma A, et al. Laparoscopic management of cholecystoenteric fistulas. J Laparoendosc Adv Surg Tech A. 2006; 16: 467-72. PMid:17004870 http://dx.doi .org /10.1089/lap.2006.16.467

[7] Glenn F, Reed C, Grafe WR. Biliaryenteric fistula. Surg Gynecol Obstet. 1981; 153: 527-31. PMid:7280941

[8] Correia MF, Amonkar DP, Navak SV, et al. Cholecystocolic fistula: A diagnositic enigma. Saudi J Gastroenterol. 2009; 15; 42-4. PMid:19568555 http://dx.doi.org/10.4103/1319-3767.45 054

[9] Swinnen L, Sainte T. Colonic Gallstone Ileus. J Belge Radiol. 1994: 77: 272-274. PMid:7829462

[10] Gaillard F, Stella D, Gibson R. Cholecystocolonic fistula diagnosed with CT-intravenous cholangiography. Australas Radiol. 2006; 50; 484-6. PMid:16981948 http://dx.doi.org/10.1111/j.1 440-1673.2006.01632.x

[11] Moreno Ruiz FJ, del Rey Moreno A, Suescun Garcia RM, et al. Treatment of cholecystoduodenal fistula in the era of laparoscopy. Rev Esp Enferm Dig. 2001; 93: 715-20. PMid:11995371

[12] Reisner RM, Cohen JR. Gallstone ileus. A review of 1,001 reported cases. Am Surg. 1994; 60: 441-6. PMid:8198337
[13] Hall JC, Hall JL. ASA status and age predict adverse events after abdominal surgery. J Qual Clin Pract. 1996; 16(2): 103-108. PMid:8794400

[14] Day EA, Marks C. Gallstone ileus. Review of the literature and presentation of thirty-four new cases. Am J Surg. 1975; 129: 552-8. http://dx.doi.org/10.1016/0002-9610(75) 90315-3

[15] Mittendorf EA, Goel A, Seaman D. Image of the month. Cholecystocolonic fistula. Arch Surg. 2004; 139: 907. PMid:15302703 http://dx.doi.org/10.1001/archsurg.139.8.907

[16] Chaffee JS. Cholecystocolic fistula with large bowel hemorrhage. Case report. Ann Surg. 1960; 152: 901-4. PMid:13692133 http: //dx.doi.org/10.1097/00000658-196011000-00019

[17] $\mathrm{Hu} \mathrm{D}$, Ren J, Wang $\mathrm{G}$, et al. Persistent inflammationimmunosuppression catabolism syndrome, a common manifestation of patients with enterocutaneous fistula in intensive care unit. Journal of Trauma and Acute Care Surgery. 2014; 76(3): 725729. PMid:24553541 http://dx.doi.org/10.1097/TA.0b013e 3182aafe6b

[18] Lynch A, Delaney C, Senagore A, et al. Clinical Outcome and Factors Predictive of Recurrence After Enterocutaneous Fistula Surgery. Ann Surg. 2004; 240(5): 825-831. PMid:15492564 http: //dx.doi.org/10.1097/01.sla.0000143895.17811.e3

[19] Aziz A, Sheikh I, Jawaid M, et al. Indications and complications of Loop ileostomy. Jl of Surgery Pakistan. 2009; 14 (3): 128-131.

[20] Okada N, Hirooka Y, Itoh A, et al. Cholecystocolonic fistula preoperatively diagnosed by endoscopic ultrasound of the colon. JGH. 2005; 20: 1621-1624.

[21] Xie B, Liu H, Mu W. Recurrent lower gastrointestinal bleeding: Diagnosis and therapy. Gastroenterology. 2011; 140(1): e9e10. PMid:21110962 http://dx.doi.org/10.1053/j .gastro. 2010.01 .061

[22] Lee Jw, Kim MY, Kim YJ, et al. CT of acute lower GI bleeding in chronic cholecystitis: concomitant pseudoaneurysm of cystic artery and cholecystocolonic fistula. Clin Radiol. 2006; 61(7): 634636. PMid:16784952 http://dx.doi .org/10.1016/j.crad. 20 06.02 .007

[23] Singh AK, Gervais D, Mueller P. Cholecystocolonic fistula: serial CT imaging features. Emerg Radiol. 2004; 10 (6): 301-302. PMid: 15278710 